\title{
Studies on the Computer Control Methods for Marine Environment Moni- toring Data
}

\author{
Zhang Hongxin*, Duan Kanghong and Zhang Ying
}

North China Sea Marine Technical Support Center of State Oceanic Administration, Qingdao City, Shandong Province, China, 266000

\begin{abstract}
With the rapid development of socialist market economy, China's monitoring of marine improved at a high speed. As there are more and more kinds of marine monitoring programs, the level of monitoring technology has been improved obviously, and monitoring data resources have increased constantly in number. Under the influence of the good development background of marine monitoring, the paragraphs below will start from discussing a data quality control method and a monitoring data quality control system to briefly introducing the computer control over marine environment data quality. The use of these two computer control methods for data quality has fundamentally improved the data quality of China's marine environment monitoring service, and laid a solid foundation for China's whole competitiveness in the international market.
\end{abstract}

Keywords: Marine environment, Monitoring data, Computer, Control.

\section{INTRODUCTION}

\subsection{The Requirements of Marine Monitoring Data Qual- ity}

Quality decides whether the nature of a product or work program is good or bad. To improve the quality of marine environment monitoring data [1-4], it's necessary to ensure that monitoring data will meet the following requirements: firstly, accuracy and precision. Accuracy requires that monitoring results should keep consistent with the true value. This index can effectively reflect whether there is error in a monitoring system and the error magnitude. It's an important safeguard for the reliability of monitoring results. Precision is the specific embodiment of the disparity of multiple measuring results. It mainly reflects whether there is error in the test procedure of an analytical method or monitoring system and the error magnitude. Secondly, the integrity can effectively reflect the validity of marine monitoring data. Integrity can reflect whether monitoring operation is carried out in accordance with the relevant requirements. Only when integrated, continuous and effective monitoring data is obtained can the actual demand of monitoring expectations be met. To make clear whether monitoring data is complete, it's usually feasible to judge whether monitoring program is complete, whether monitoring frequency meets the actual demand, and whether there is missing monitoring and reporting. Thirdly, there are representativeness and comparability. There is a great variety of marine environment monitoring data, so the content of quality evaluation should be featured not only by tightness, accuracy and integrity, but also by

*Address correspondence to this author at the North China Sea Marine Technical Support Center of State Oceanic Administration, Qingdao City, Shandong Province, China; E-mail: bhjszx_zhx@163.com representativeness and comparability, so as to meet the actual demand of many types of data structures.

\subsection{The Content of Marine Monitoring Data}

To meet the actual demand of a complex marine environment, China has made a comprehensive use of many effective monitoring means. Marine monitoring data quality index, with the combination of the actual characteristics of many quality control means, has fully embodied the request for accuracy and tightness in marine environment quality monitoring index [5-8]. So the main content of quality assessment can be defined as: data integrity, rationality and representativeness. Data integrity is assessed according to actual monitoring requirements in the premise that a goal is set based on tasks. Data rationality and representativeness require that marine environment's actual features should be made clear, and various effective monitoring methods should be used together to figure out whether monitoring data fits in with the actual features of marine environment and meets the actual demand of environmental changes.

\section{THE IMPORTANCE OF MARINE ENVIRONMENT MONITORING DATA QUALITY}

It's explicitly stipulated in The Metrological Law of the People's Republic of China, "To meet the society's development demand, it's necessary to provide the society with a notarized product quality inspection body. Only after a metrological administrative department in the people's government at or above province level normalizes, it can it have the fundamental rights to engage in measuring work." It's requested in Measures for the Authentication Management over Product Quality Inspection Bodies, "The issuing of trading certificate, product quality evaluation and achievement appraisal must be based on the relevant data obtained 


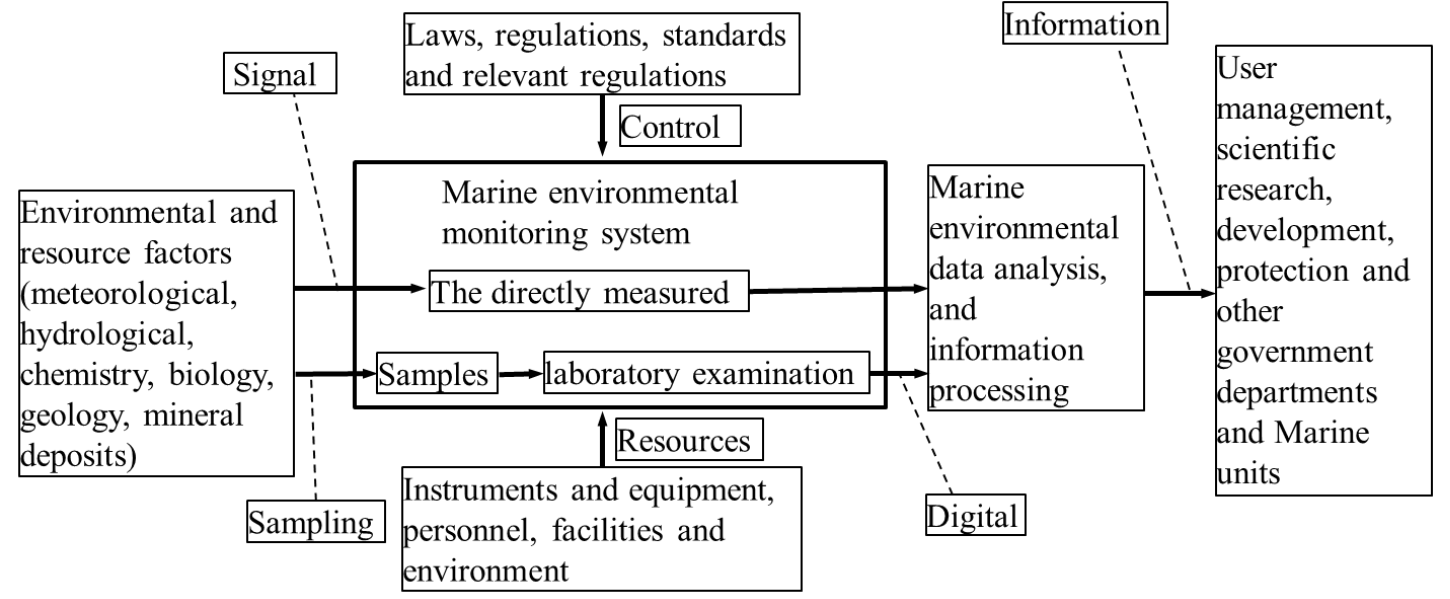

Fig. (1). Marine environment monitoring procedures.

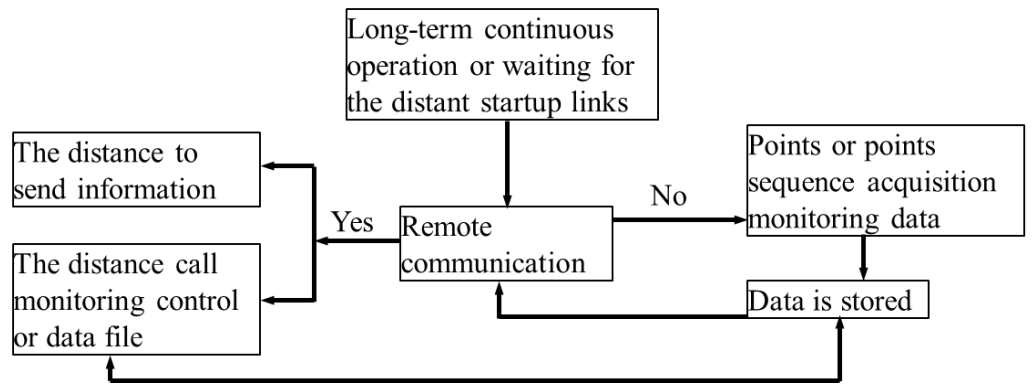

Fig. (2). Procedural model for field monitoring system software.

from a product quality inspection body after passing the actual requirement of metrological certification." Therefore, marine environment monitoring authority must pass the related examination before being able to show authentic and reliable data. Fig. (1) below is a process schematic for China's marine environment monitoring work. That is to say, computer control over marine environment monitoring data quality must first meet the requirements of General Administration of Quality Supervision, Inspection and Quarantine of the People's Republic of China and obtain the certificate of metrological certification before being able to meet the requirement for the control over marine environment monitoring data quality. Thus it can be seen that marine environment monitoring department must pay high attention to data quality control.

\section{STUDIES ON THE COMPUTER CONTROL METHOD FOR MARINE ENVIRONMENT MONI- TORING DATA QUALITY}

\subsection{Computer Remote Environmental Monitoring Model}

The core of multimedia network remote control \& transmission system for marine environment is a piece of remote control \& transmission system software [9-12]. The fundamental of this software is to connect the major monitoring computer in marine environmental monitor station to a remote monitoring computer through communication networks or the Internet, to examine the change of the physical parameters in the various monitoring points controlled by the computers in a marine environment field in real time by the use of remote monitoring software, and execute a remote application program in the host computer in marine environment or print it remotely. In addition, it's also feasible to transmit the monitoring data in the host computer in marine environment remotely and bi-directionally, to achieve the purpose of invoking remote data (Fig. 2).

Remote monitoring and transmission technique is a combination of advanced automation technology as well as computer and network technique with monitoring technology and prediction technique for emergent oil contamination and solid waste in marine environment and with multimedia computer network and communication network. It's a modern wide-range and multi-point remote monitoring and transmission system used to monitor environments in real time and control the computer-control system in environmental monitor station remotely (Fig. 3). Remote monitoring computer can also be used to look over the change of the physical parameters in all the monitoring points controlled by the computers in marine environment field. When a significant change takes place to marine environment, the administrative department, decision-making section and 


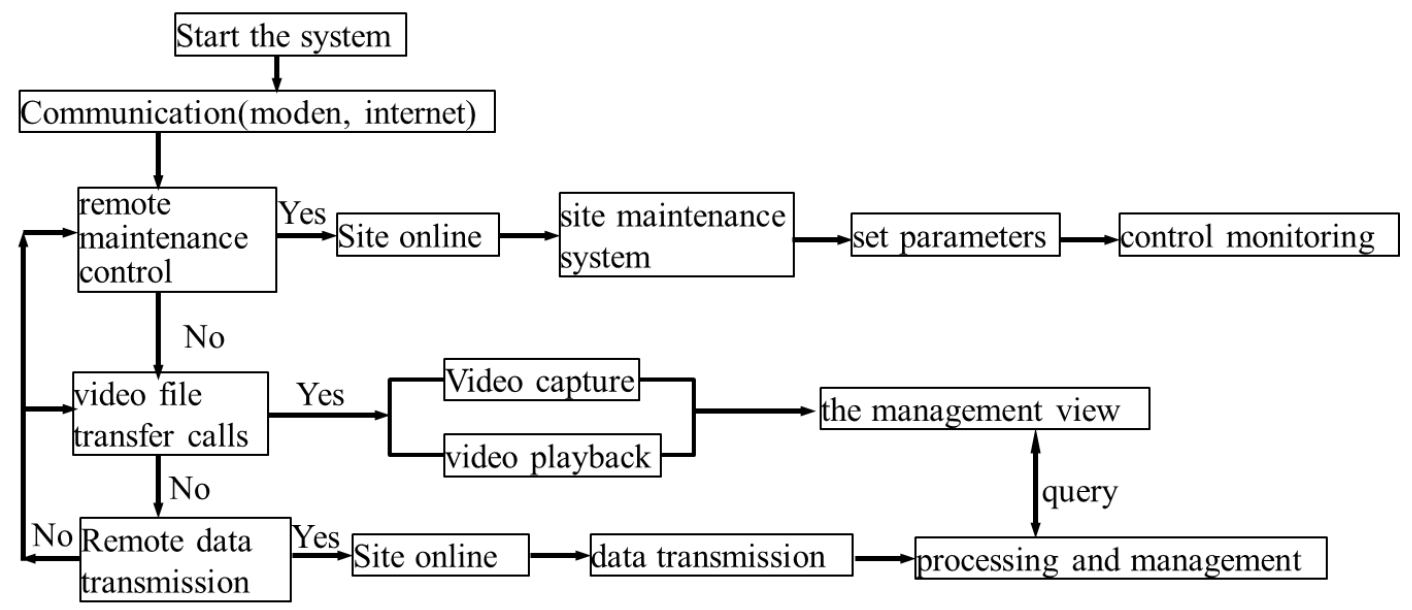

Fig. (3) Procedural model for remote monitoring and transmission.

Table 1. Some monitoring data about TP and PO4-P in the total marine pollutants in a water area of China

\begin{tabular}{|c|c|c|}
\hline Monitoring Station Location & TP/mg.L ${ }^{-1}$ & Po4-p/ mg.. $^{-\mathbf{1}}$ \\
\hline \hline YA1 & 0.046 & 0.023 \\
\hline YA2 & 0.031 & 0.028 \\
\hline YA3 & 0.061 & 0.026 \\
\hline YA4 & 0.060 & 0.024 \\
\hline
\end{tabular}

relevant experts can check the physical parameters in all the monitoring points at any time. Then, they can develop a corresponding solution and feed it back to the monitoring points through network systems, to provide important technical support for the establishment of a real-time monitoring system in marine environment and for environment monitoring \& management department, decision-making section and experts to make a real-time study on the dynamic monitoring results of a remote environment field.

\subsection{Data Quality Control Method}

In China, the computer control over marine environment monitoring data quality has always been on manual basis. Under normal conditions, operators, after data auditing, complete data quality control. However, manual control needs a large amount of time and the final auditing effect is bad, difficult to control marine environment monitoring data well. In recent years, with the development of economy, China has combined manual monitoring and computer control, with manual control second to computer control, thus comprehensively improving the control effect of marine environment monitoring data. Several common data quality control methods are shown below.

1). Conduct control based on the normal value range of marine elements
A summary of marine environment monitoring experts' experience shows: After determining the normal value range of each marine element, we can compare it with monitoring data to make clear the accuracy and precision of monitoring data. If the data obtained in monitoring process is beyond the range or isn't within the range, this data is absolutely an improper value.

2). Conduct control based on the relationship among marine elements

There is a necessary connection among the elements in marine environment monitoring process, and the connection is one of the main bases for the computer control over marine environment monitoring data quality. Therefore, monitors should judge the authenticity and reliability of monitoring data according to the regularity and connectivity among the marine elements. Firstly, they should make an inspection using the different forms of relations among the elements. Organic nitrogen TON and mineral nitrogen TIN make up total nitrogen TN, which mainly includes NH4-N and NO3$\mathrm{N}$, so the quantity of total nitrogen $\mathrm{TN}$ must be larger than that of total nitrogen TN. Tab. 1 below shows some monitoring data about TP and PO4-P in the total marine pollutants in a water area in China. The statistical result in Table $\mathbf{1}$ obviously indicates that the concentration of PO4-P is apparently lower than that of TP. 
Table 2. Monitoring data about $\mathrm{COD}_{\mathrm{Cr}}$ and $\mathrm{BOD}_{5}$ in the total marine pollutants in a sea area of China.

\begin{tabular}{|c|c|c|}
\hline Station Location & COD $_{\mathrm{Cr}} / \mathbf{m g . \mathbf { L } ^ { - 1 }}$ & BOD $_{\mathbf{5}} / \mathbf{m g . L}^{\mathbf{- 1}}$ \\
\hline \hline DY1 & 41.2 & 23.5 \\
\hline DY2 & 39.5 & 22.2 \\
\hline DY3 & 32.1 & 22.7 \\
\hline DY4 & 27.3 & 16.8 \\
\hline
\end{tabular}

Table 3. The mean value of some monitoring elements in the same location at different times in May, August and October of a certain year in a sea area of China

\begin{tabular}{|c|c|c|c|}
\hline Monitoring Elements & May & August & October \\
\hline \hline COD/mg. $\mathrm{L}^{-1}$ & 17.43 & 78.98 & 9.02 \\
\hline TP/mg. L $^{-1}$ & 0.14 & 0.24 & 0.06 \\
\hline CU/ug. L ${ }^{-1}$ & 223.00 & 3.96 & 0.21 \\
\hline PB/ug. L L $^{-1}$ & 1.96 & 5.53 & 0.72 \\
\hline
\end{tabular}

Secondly, monitors can also inspect the control effect of marine environment monitoring data quality by clarifying the relationship among the monitoring elements of the same substance. Through water decomposition experiment, we can learn that to identify the level of water pollution, we must first know the actual content of $\mathrm{COD}_{\mathrm{Cr}}, \mathrm{COD}_{\mathrm{Mn}}$ and $\mathrm{BOD}_{5}$ in water. Some organic substances in ordinary water can hardly be oxidated in $\mathrm{COD}_{\mathrm{Mn}}$, and the substances that cannot be oxidated by $\mathrm{COD}_{\mathrm{Mn}}$ can usually participate in an oxidizing reaction in $\mathrm{COD}_{\mathrm{Cr}}$. Thus it can be seen that the quantity of $\mathrm{COD}_{\mathrm{Cr}}$ in water is certainly larger than that of $\mathrm{COD}_{\mathrm{Mn}}$. Table 2 below shows the monitoring data about $\mathrm{COD}_{\mathrm{Cr}}$ and $\mathrm{BOD}_{5}$ in the total marine pollutants in a sea area of China. It can be clearly seen from Table 2 that the value of $\mathrm{BOD}_{5}$ is smaller than that of $\mathrm{COD}_{\mathrm{Cr}}$.

Finally, monitors can also control the result of the computer control over marine environment monitoring data quality in accordance with the time relationship among marine elements. If the time relationship among marine elements is used for control, monitors will be required to monitor the concentration of the same element in the same monitoring location at different times, to judge the accuracy of monitoring data according to the change of concentration. Table 3 below shows the mean value of some monitoring elements in the same location at different times in May, August and October of a certain year in a sea area of China. It can be clearly seen from Table 3 that the mean value of this element is largest in August and smallest in October.

\subsection{The Design of a Quality Control System for Monitor- ing Data}

Apart from researching the content of the above marine quality control and the quality control method, we must design an effective quality control system for monitoring data by combining the present situation of China's marine environment monitoring. The design of a quality control system for monitoring data should be based on the following aspects.

\section{1). System framework and environment}

Comprehensive use will be made of client-side and server structure in the system and DELPHI language will be used for completing software development. In addition, designers should also use Super Map Objects' relevant components comprehensively to accomplish data quality analysis and examination. About database, ORCALE $10 \mathrm{~g}$ is generally adopted.

\section{2). Database}

Based on the existing database for the computer control over marine environment monitoring data, we should supplement inspection standards, monitoring schemes and user management databases appropriately. Only the comprehensive use of databases can fundamentally meet the actual demand for the quality control over marine environment monitoring data. Finally, about the design of a quality control system for monitoring data, attention should also be paid to the importance of user right control, inspection standard, maintenance of monitoring scheme, and data quality audit. Only by improving the quality of various monitoring work constantly can we, in the premise of optimizing the design scheme, improve the level of the computer control over marine environment monitoring data quality in China.

\section{CONCLUSION}

In a word, marine environment monitoring quality control is a key content of marine environment monitoring work. 
To improve the quality of marine environment monitoring work, it's imperative to adopt a necessary and scientific control method, to lay a solid foundation for the improvement of monitoring efficiency at the same time of guaranteeing data quality. The main purpose of the quality control over marine environment monitoring data is to meet the actual demand of monitoring quality by the use of rational technologies and activities. Marine environment quality monitoring department won't comprehensively improve the level of the quality control over marine environment monitoring data unless monitoring marine environment quality actively develops a clear data quality control method and designs an optimal quality control system for monitoring data.

\section{CONFLICT OF INTEREST}

The authors confirm that this article content has no conflicts of interest.

\section{ACKNOWLEDGEMENTS}

Declared none.

\section{REFERENCES}

[1] V. M.P. Bouchet, A. Elisabeth, R. Brage, and R. J. Telford "Benthic foraminifera provide a promising tool for ecological quality assessment of marine waters", Ecological Indicators, vol.23, pp.66$75,2012$.

[2] J. G. Ferreira, J. H. Andersen, A. Borja, S. B. Bricker, J. Camp, M. C. Da Silva, E. Garcs, A.-S. Heiskanen, C. Humborg, L. Ignatiades, C. Lancelot, A. Menesguen, P. Tett, N. Hoepffner and U. Claussen, "Overview of eutrophication indicators to assess environmental status within the European marine strategy framework directive", Estuarine, Coastal and Shelf Science, vol.93, no.2, pp.117-131, 2011.

[3] B. Beliaeff, and D. Pelletier, "A general framework for indicator design and use with application to the assessment of coastal water quality and marine protected area management", Ocean \& Coastal Management, vol.54, no.1, pp. 84-92, 2011.
[4] K. Kennedy, T. Schroeder, M. Shaw, D. Haynes, S. Lewis, C. Bentley, C. Paxman, S. Carter, E. Vittorio, M, Brando, L, Bartkow, Hearn, and Jochen F. Mueller, "Long term monitoring of photosystem II herbicides-Correlation with remotely sensed freshwater extent to monitor changes in the quality of water entering the Great Barrier Reef, Australia", Marine Pollution Bulletin, vol.65, no.4, pp.292-305, 2012.

[5] S. Martin, W. Roanne, A. M. Roth, and B. M. Matsuyama, "Use of automated passive acoustic monitoring methods for monitoring for marine mammals in conjunction with US Navy Mid-frequency Active Sonar training events", The Journal of the Acoustical Society of America, vol.134, no.5, pp.4045-4045, 2013.

[6] M. Mecozzi, M. Pietroletti, F. Oteri, and R. Di Mento, "Applications of PCA to the monitoring of hydrocarbon content in marine sediments by means of gas chromatographic measurements", Principal Component Analysis-Engineering Applications, vol. 65, 2012, Available from: http://www.intechopen.com/books/principalcomponent-analysis-engineering-applications/applications-of-pcato-the-monitoring-of-hydrocarbon-content-in-marine-sediments-bymeans-of-gas-chr

[7] A. Kumar, C. Johnson, J. Rivers, J. Nissen, and J. Bell, "US Navy application and interest in passive acoustics for estimation of marine mammal population density", The Journal of the Acoustical Society of America, vol.136, no.4, pp.2246-2246, 2014.

[8] T.-H. Lin, H.-Y. Yu, C.-F. Chen, and L.-S. Chou, "Passive acoustic monitoring on the seasonal species composition of cetaceans from a marine observatory", The Journal of the Acoustical Society of America, vol.136, no.4, pp.2074-2074, 2014.

[9] S. Singhal, A. K. Gankotiya, S, Agarwal, T. Verma, "An investigation of wireless sensor network: a distributed approach in smart environment", Advanced Computing \& Communication Technologies (ACCT), $20122^{\text {nd }}$ International Conference on, IEEE, 2012.

[10] N. Celandroni, E. Ferro, A. Gotta, G. Oligeri, C. Roseti, M. Luglio, I. Bisio, M. Cello, F. Davoli, A. D. Panagopoulos, M. Poulakis, S. Vassaki, T. De Cola, M. A. Marchitti, Y. F. Hu, P. Pillai, S. Verma, K. Xu and G. Acar, "A survey of architectures and scenarios in satellite based wireless sensor networks: system design aspects", International Journal of Satellite Communications and Networking, vol.31, no.1, pp.1-38, 2013.

[11] M. J. Booysen, Z. Sherali and G-J. Van Rooyen, "Survey of media access control protocols for vehicular ad hoc networks", IET communications, vol. 5, no. 11, pp. 1619-1631, 2011.

[12] Y. Wang, C. Qi, and H. Pan, "Design of remote monitoring system for aquaculture cages based on $3 \mathrm{G}$ networks and ARM-Android embedded system", Procedia Engineering, vol. 29, pp.79-83, 2012. 